\title{
The characterization of conserved binding motifs and potential target genes for $M$. tuberculosis MtrAB reveals a link between the two-component system and the drug resistance of $M$. smegmatis
}

\author{
Yuqing Li, Jumei Zeng, Hua Zhang, Zheng-Guo He*
}

\begin{abstract}
Background: The two-component systems of Mycobacterium tuberculosis are apparently required for its growth and resistance in hostile host environments. In such environments, MtrAB has been reported to regulate the expression of the M. tuberculosis replication initiator gene, dnaA. However, the dnaA promoter binding sites and many potential target genes for MtrA have yet to be precisely characterized.

Results: In this study, a 7 bp sequence motif in the dnaA promoter region was identified for MtrA binding using DNasel footprinting assays and surface plasmon resonance (SPR) analysis. Approximately 420 target genes potentially regulated by MtrA, including the isoniazid inducible gene iniB, were further characterized from M. tuberculosis and M. smegmatis genomes. When assayed using quantitative real-time PCR (qRT-PCR), many of the target genes demonstrated significant expression changes when the antisense mRNA of the mtrA gene was expressed in M. smegmatis. The recombinant mycobacteria grew in length and were more sensitive to two antituberculosis drugs, isoniazid and streptomycin.
\end{abstract}

Conclusions: These findings yield critical information about the regulatory mechanisms of the MtrAB twocomponent system and its role in the drug resistance of $M$. smegmatis.

\section{Background}

M. tuberculosis is one of the most devastating human pathogens, and its threat to human health has intensified with the emergence of multidrug-resistant tuberculosis (TB) and the worldwide prevalence of co-infection with HIV [1,2]. Two-component regulatory systems (TCRs) are widely distributed among bacteria and plants and enable organisms to regulate gene expression in response to a variety of environmental stimuli $[3,4]$. Some TCRs are clearly involved in regulating the virulence of pathogenic bacteria [3].

The $M$. tuberculosis genome contains 11 paired TCRs and several orphan kinases and regulators [5]. Several TCRs are apparently required for the growth of M. tuberculosis under specific conditions [6-8]; for

\footnotetext{
* Correspondence: hezhengguo@mail.hzau.edu.cn National Key Laboratory of Agricultural Microbiology, Center for Proteomics Research, College of Life Science and Technology, Huazhong Agricultural
} University, Wuhan 430070, China example, $m p r A-m p r B$ is important for the maintenance of persistence [6]. Of the $11 \mathrm{M}$. tuberculosis TCRs, only the $m \operatorname{tr} A-m \operatorname{tr} B$ system has been confirmed as essential for in vitro and in vivo survival of $M$. tuberculosis [9-11]. Several recent reports show that the regulator MtrA modulates $M$. tuberculosis proliferation by regulating $d n a A$ expression and binding the origin of replication [12,13]. In Mycobacterium avium, morphotypic multidrug resistance requires the presence of an MtrA homologue [14].

The $m \operatorname{tr} A B$ system has been successfully deleted in Corynebacterium glutamicum, an industrial amino acid production strain [15]. Mutant cells lacking $m \operatorname{tr} A B$ showed a different cell morphology and were more sensitive to penicillin, vancomycin, and lysozyme, however, they were more resistant to ethambutol [15]. The expression of some genes involved in both peptidoglycan metabolism and osmoprotection was also substantially changed [15]. Therefore, MtrAB in C. glutamicum 
is thought to be involved in regulating cell wall metabolism and osmoprotection.

The M. tuberculosis MtrAB system is thought to be involved in the expression of many target genes and contributes to the pathogen survival and resistance within its host tissue. However, these target genes and their MtrA binding sites have not been clearly established. In the current study, we have identified conserved sites for the recognition of MtrA in the dnaA promoter, as well as approximately 420 potential target genes. Further in vivo studies concerning a related organism, M. smegmatis, reveal changes in both cell morphology and drug resistance when MtrA gene expression is inhibited. The data presented here significantly enhance our understanding of the regulatory mechanisms of the essential two-component MtrAB system and its role in mycobacterial drug resistance.

\section{Results \\ MtrA interacted with the regulatory region of the $M$. tuberculosis dnaA gene}

Bacterial one-hybrid assays confirmed the interaction between MtrA and the regulatory sequence of the dnaA initiator gene. The $d n a A$ promoter region was cloned into the reporter genes upstream of HIS3-aadA and the reporter vector pBXcmT (Fig. 1A). As shown in Fig. 1B, the co-transformant strain with the $d n a A$ promoter and MtrA was observed to grow well on the screening medium. In contrast, there was no growth for the strain containing either MtrA or the dnaA promoter alone. In addition, neither the co-transformant strain containing an unrelated DNA, SsoDNA (Additional file 1), nor MtrA did grew, indicating that this DNA cannot interact with MtrA (Fig. 1B). Thus, MtrA specifically interacted with the $d n a A$ gene promoter.

The interaction of the purified MtrA protein with the $d n a A$ promoter was confirmed by the interaction with the DNA on the chip. As shown in Fig. 1C, the biotinylated promoter DNA was first associated with the streptavidin (SA) chip (GE Healthcare). When an increasing concentration of MtrA protein (100-500 nM) was passed over the chip surface, a corresponding increasing response value was observed. This again indicated that the MtrA protein could bind with the $d n a A$ promoter DNA (Fig. 1C). In contrast, heated inactive protein showed no response when it was passed over the chip (Fig. 1C). When an unspecific DNA, the promoter of Rv0467, was coated on the chip, no significant association for MtrA was observed (Additional file 2). In a further confirmatory experiment, $200 \mu \mathrm{M}$ unlabeled promoter DNA was also added along with the MtrA protein. This DNA competed with that on the chip for the available MtrA; here, a significantly lower response was observed compared to a control with no competition (Fig. 1D).

\section{Characterization of the DNA-box motif in the dnaA promoter that allows MtrA binding}

Several short DNA fragments (S1-S5) were used to precisely determine the DNA-box motif for the MtrA in this promoter region (Fig. 2A). As shown in Fig. 2B, a specific protein/DNA complex was observed on S1, S2, and S5, indicating that MtrA could recognize these DNA substrates. In contrast, no binding activity was observed for substrates S3 and S4, both of which lacked the 5-CACGCCG-3 or 5-CACGAGG-3 sequence box (Fig. 2A). Further confirmation of the specific interaction was obtained by conducting the competing surface plasmon resonance (SPR) assay with the unlabeled DNA fragments. As shown in Additional file 3, a significantly lower response was observed when either the unlabeled S2 or S5 was added together with MtrA, which indicated that they could compete the binding of MtrA with the promoter DNA on the chip. Therefore, these two sequence motifs appeared to be essential for the MtrA binding with the $d n a A$ regulatory region.

The interaction between MtrA and these two sequence boxes was further confirmed by DNase I footprinting assays (Fig. 3). Regions that contain these two boxes were significantly protected when MtrA was present. Protection at $\mathrm{S} 6$ occurred at all MtrA concentrations while the protection of S7 was dependent on the concentration of MtrA. This suggests that MtrA has different binding affinities with these regions.

We characterized two sequence boxes for the recognition of MtrA within the $d n a A$ promoter, situated immediately downstream of promoters P1 and P2. The binding sequence boxes and their situation within the $d n a A$ promoter are summarized in Fig. $2 \mathrm{C}$.

\section{Characterization of potential target genes regulated by MtrA in mycobacterial genomes}

We searched the intergenic regions of the $M$. tuberculosis and $M$. smegmatis genomes extensively based on the two sequence motifs for MtrA in the $d n a A$ gene promoter region. To validate the target genes, several regulatory regions of the genes were amplified. The DNA-binding activities of MtrA were examined using EMSA assays. As shown in Fig. 4, the regulatory sequence of a predicted target gene, isoniazid inducible gene iniB (rv0341), could be recognized by MtrA. A specific DNA/protein complex band was also observed. In addition, MtrA was able to bind with two target promoter DNA sequences of Rv0574 (a hypothetical protein) and Rv3476 (KgtP), producing a corresponding DNA/protein band (Fig. 4A). The positive target DNA was shown to bind with MtrA, 


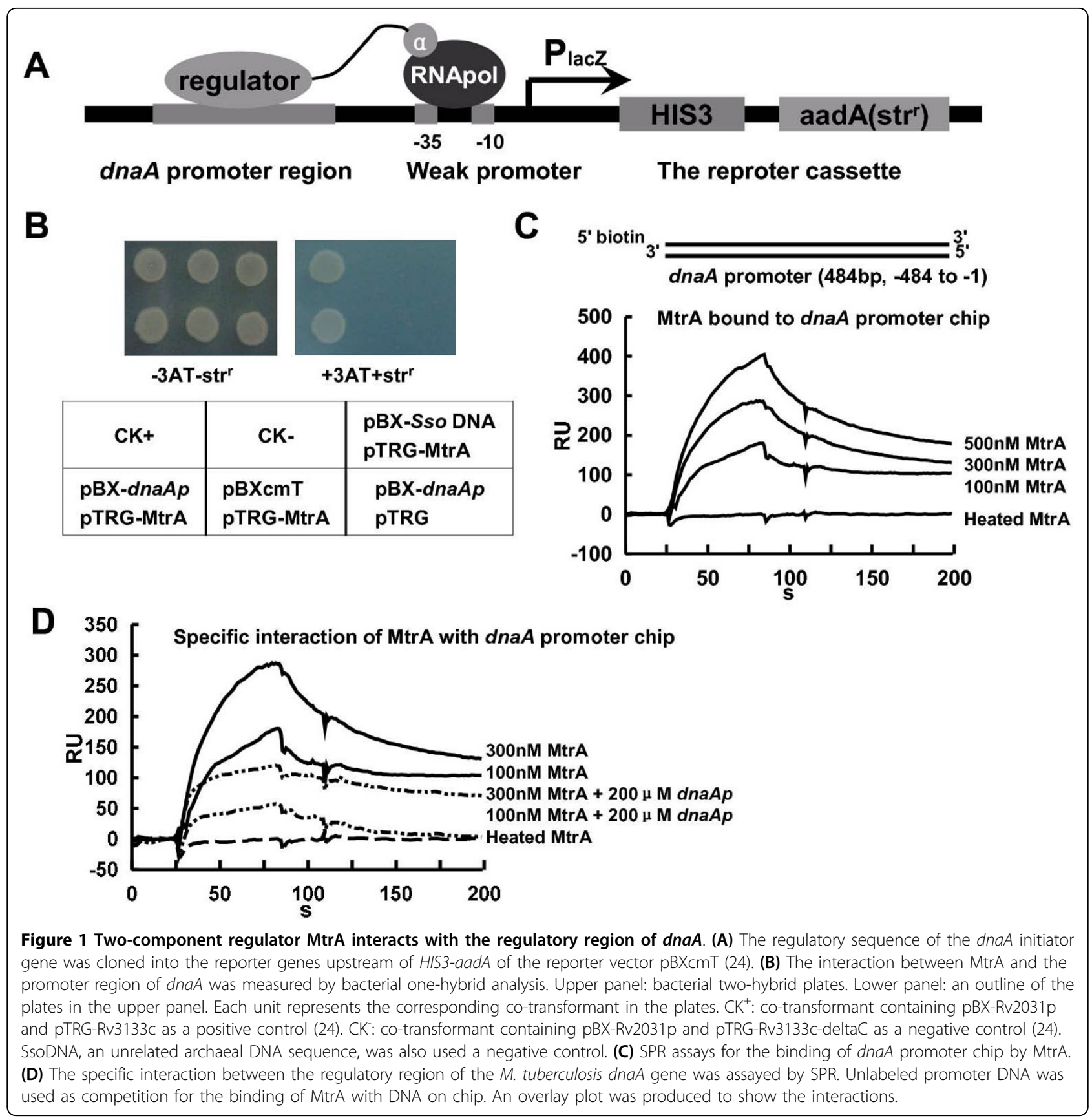

while the negative DNA was not. The 7 bp sequence motif could also be found in the promoter regions of two previously characterized target genes, CgmepA and CgproP, in C. glutamicum. Interestingly, M. tuberculosis MtrA bound with the regulatory sequences and produced specific shifted bands (Fig. 4A).

A further logo assay for the consensus sequence was conducted using the WebLogo tool [16]. A more general conserved motif for MtrA recognition was mapped out (Fig. 4B). In all, 155 potential target genes were characterized from the M. tuberculosis genome (Additional file
4), and 264 genes were characterized from the M. smegmatis genome (Additional file 5).

Effects of mtrA gene expression level on mycobacterial drug resistance and cell morphology

The mRNA antisense expression of the $m t r A$ gene in $M$. smegmatis showed a regulatory effect of $m t r A$ on mycobacterial drug resistance and cell morphology [17]. No substantial change was observed for the general growth of the recombinant mycobacterial strains. However, as shown in Fig. 5A, the recombinant mycobacterial 


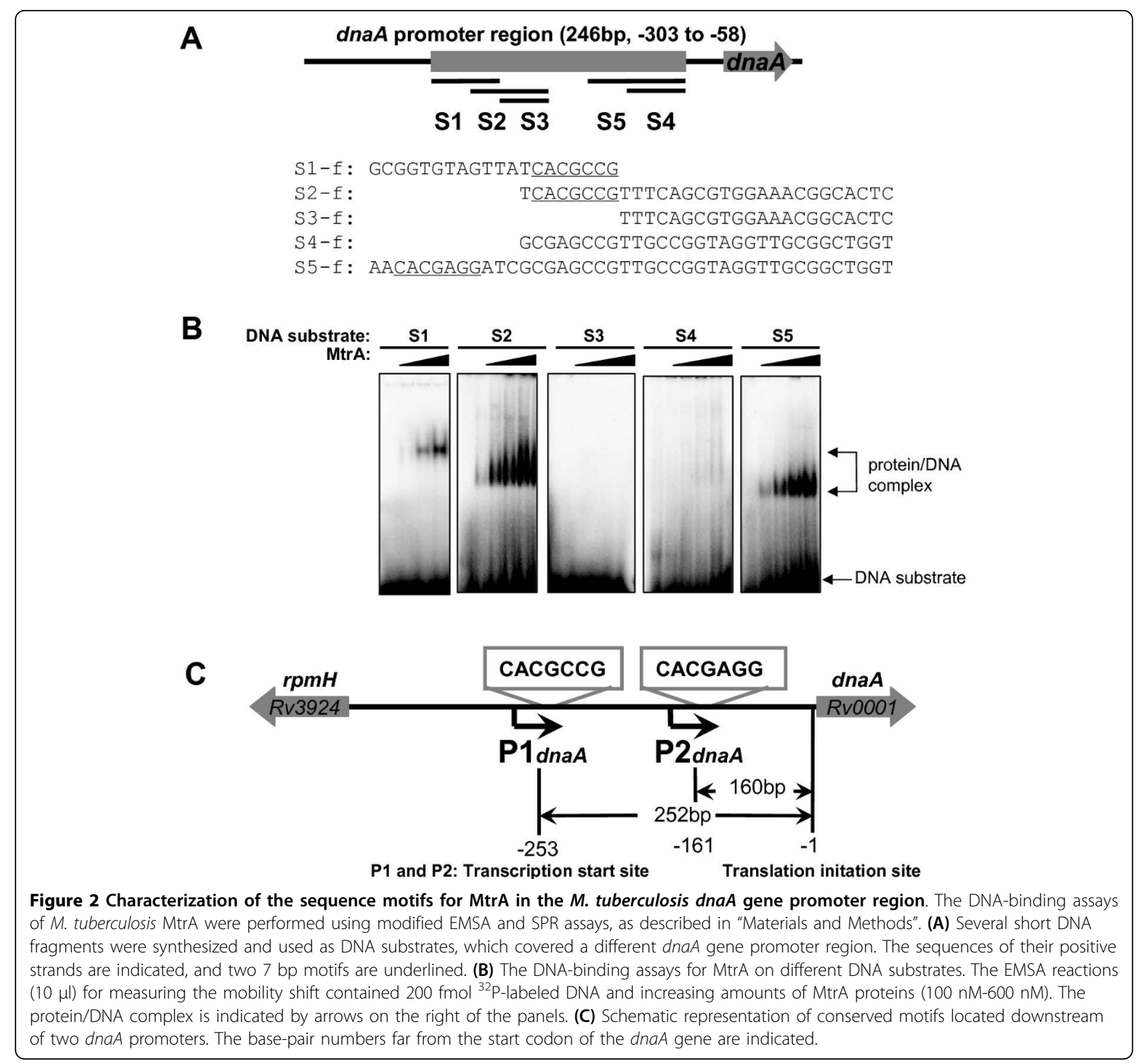

cells became sensitive to the anti-TB drugs isoniazid and streptomycin, as evidenced by their inhibited growth in the presence of $25 \mu \mathrm{g} / \mathrm{mL}$ of isoniazid or $0.5 \mu \mathrm{g} / \mathrm{mL}$ of streptomycin in the medium. In contrast, no noticeable inhibition was observed for two other drugs, ethambutol and rifampicinB (data not shown). With a general growth of the recombinant mycobacterial strains resulting in minimal change, the cell morphology was further examined using the scanning electron microscopy (SEM) technique. As shown in Fig. 5B, the cell lengthened when $20 \mathrm{ng} / \mathrm{mL}$ tetracycline was added to the medium to induce expression of the antisense $m t r A$ mRNA (right panel).
When relative gene expression was measured via qRTPCR as shown in Fig. 5C, the mtrA gene was only 0.38 -fold that of the wild-type strain, indicating that the expression of the $m t r A$ gene in recombinant $M$. smegmatis was greatly inhibited. The expression of the dnaA gene in the recombinant strain basically remained constant when compared with that in the wild-type strain. This was consistent with the fact that no conserved sequence motif existed within the regulatory region of this gene in M. smegmatis. Another approximately 26 potential target genes were randomly chosen to measure the expression change in the recombinant $M$. smegmatis strain (Fig. 5C). The expression levels of these genes 


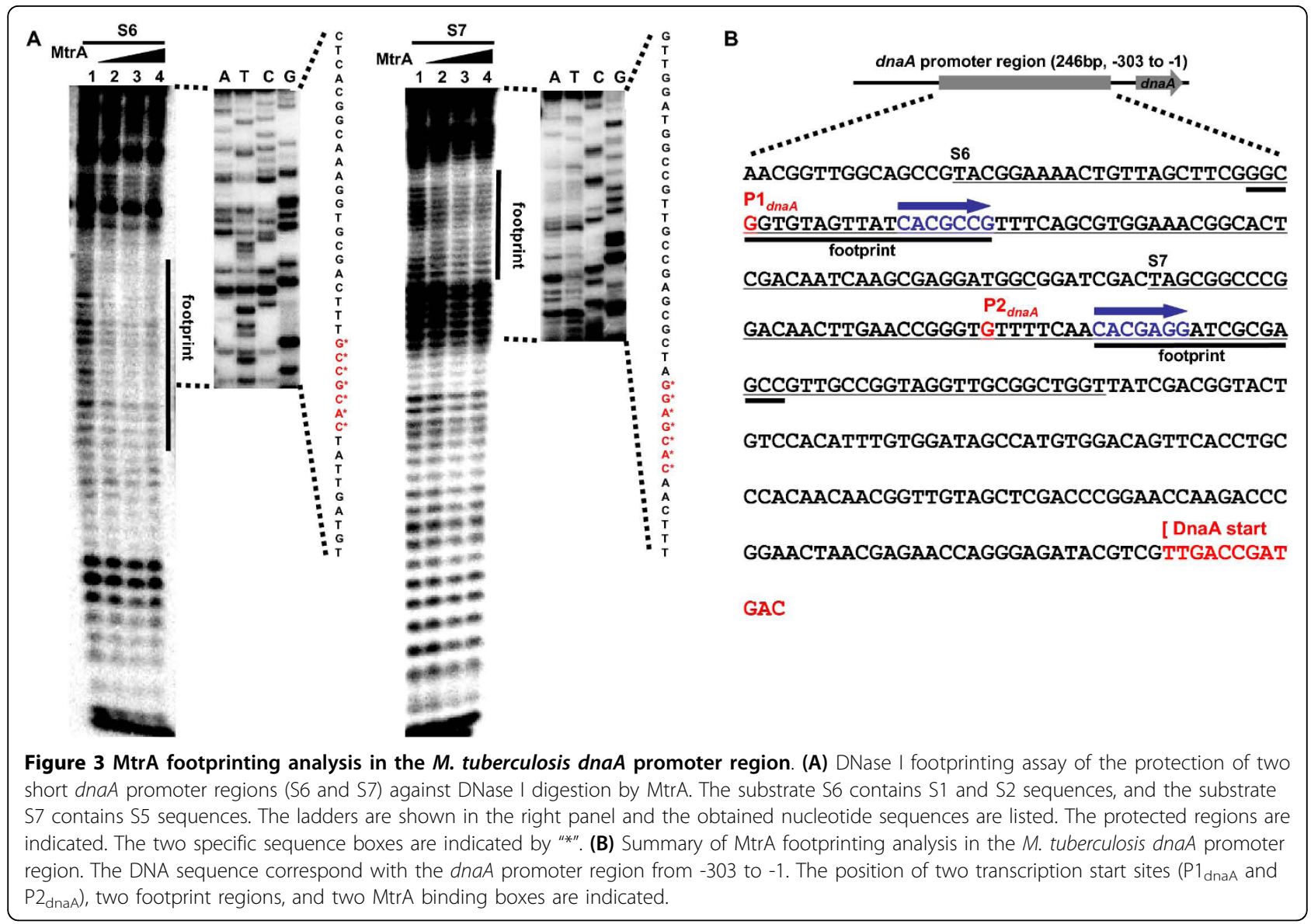

clearly changed; iniA and $m \operatorname{tr} B$ gene expression increased 2.5-fold expression (Fig. 5C), while mraZ (Msmeg_4236) and rpfB (Msmeg_5439) gene expression decreased by about 0.2 -fold (Fig. 5C).

Therefore, the inhibition of the $m t r A$ gene resulted in corresponding expression changes in many predicted target genes in M. smegmatis. The expression level of the $m$ trA gene consequently affected the drug resistance and cell morphology of M. smegmatis.

\section{Discussion}

MtrAB has been reported to regulate the expression of the M. tuberculosis replication initiator gene, dnaA [12]. However, potential binding sites for MtrA have not been clearly characterized. In addition, there are many potential target genes that also appear to be regulated by MtrA. In the current study, we identified a 7 bp conserved sequence motif for the recognition of MtrA within the dnaA promoter. About 420 potential target genes regulated by $M \operatorname{trAB}$ were predicted from the $M$. tuberculosis and M. smegmatis genomes upon searching their promoter databases. Many predicted target genes showed significant expression changes when the mtrA homologue of $M$. smegmatis was partially inhibited. The recombinant $M$. smegmatis cells increased in length and became sensitive to the anti-TB drugs isoniazid and streptomycin.

The transcription of $d n a A$ starts essentially at $\mathrm{P} 1_{d n a A}$, which is conserved in all mycobacterial species [18]. The analysis of the sequence in the upstream region of dnaA revealed a second promoter, $\mathrm{P} 2_{d n a A}$, in $M$. tuberculosis [18]. In previous in vivo experiments, MtrA bound with the regulatory region of the $d n a A$ gene [12]. In the current study, two binding motifs for MtrA were located immediately downstream from the two promoters (Fig. 2C). Therefore, MtrA can apparently interfere with the promoter activity and thus regulate the expression of the replication initiator gene. The promoter $\mathrm{P} 2_{\text {dnaA }}$ only exists in a viral strain or derivative strains such as M. tuberculosis, M. bovis and BCG, but not in $M$. avium or $M$. smegmatis [18]. This suggests that the two-component system MtrAB might contribute to the virulence of the $M$. tuberculosis complex through selective regulation of $d n a A$ gene expression. A parallel study [13] has identified a "GTCACAgcg" motif for the recognition of MtrA in the $f b p B$ promoter and the origin of replication. Interestingly, there exists a common conserved core sequence between the $9 \mathrm{bp}$ motif and 


\section{A negative \\ DNA substrate: control MtbdnaA1p Rv0341p Rv0574cp Rv3476cp CglumepAp CgluproPp}

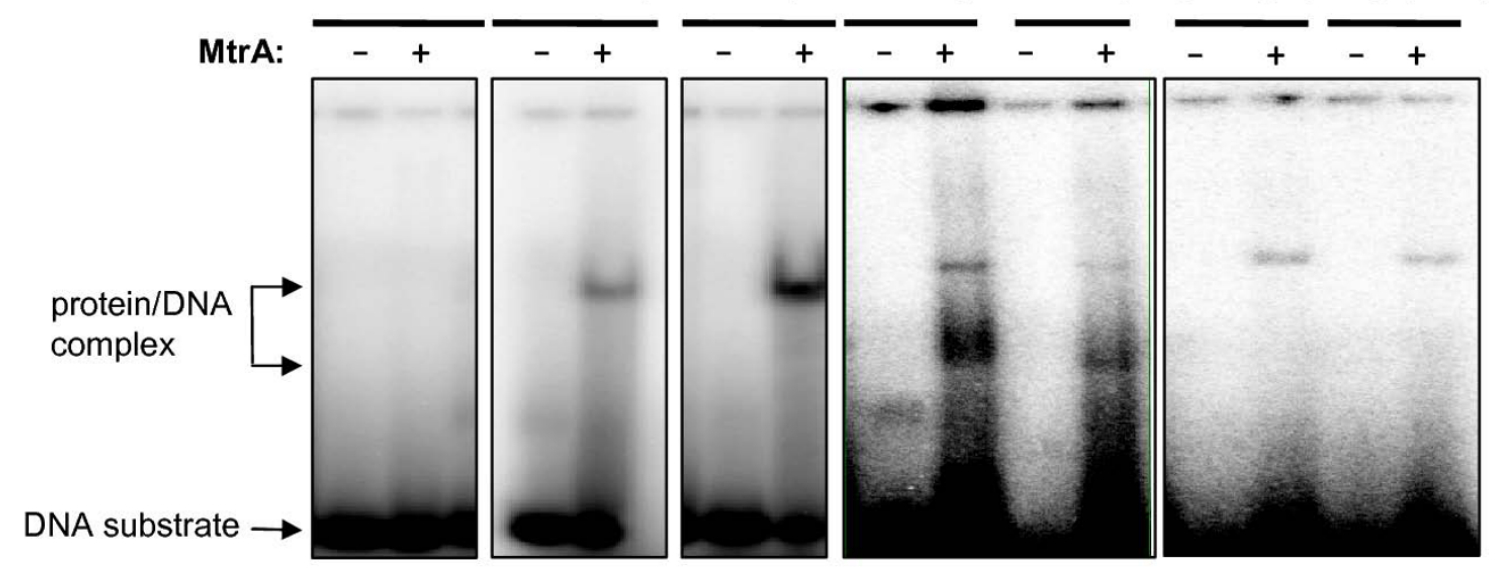

B
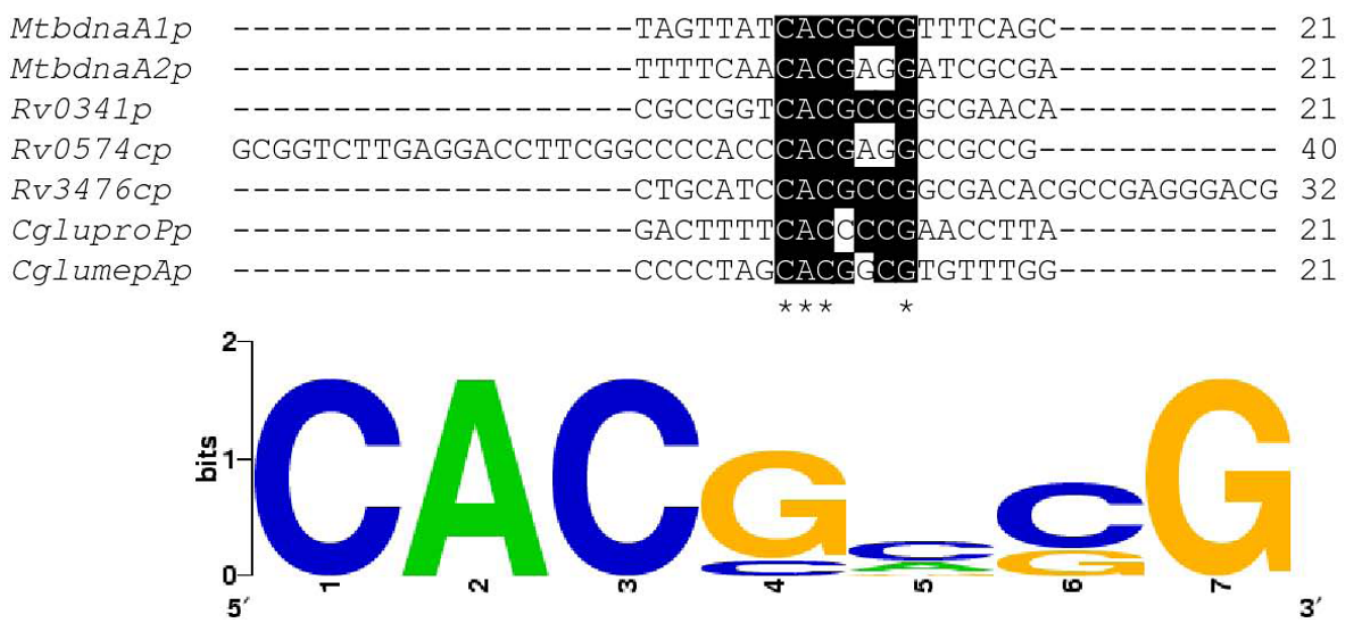

Figure 4 Characterization of the conserved sequence motif for MtrA in mycobacteria and C. glutamicum. (A) EMSA assays for validating the binding of MtrA with regulatory sequences of several potential target genes from $M$. tuberculosis. The promoter DNA of M. tuberculosis dnaA gene was used as positive control. An unrelated DNA was used as negative control. Several DNA substrates, namely, Rv0341_up, Rv0574C_up, and Rv3476__up, were amplified from their promoter regions using specific primers. Several regulatory sequences of potential target genes from C. glutamicum including CglumepAp and CgluproPp, were amplified and used as DNA substrates. (B) A blast assay for the conserved sequence motif recognition by MtrA. Sequence alignment was carried and visualized by local BioEdit software. The complete consensus sequence is indicated by the stars under the base in the upper panel. Sequence logo was generated by WebLogo tool.

the motif identified within the $d n a A$ promoter in the current study. Using a MalE-EnvZ kinase, but not the cognate partner kinase of MtrB, Rajagopalan et al suggested that the phosphorylation of MtrA had distinct regulation capacities. However, only $5 \%$ of the MtrA protein was shown to be phosphorylated [13]. In the present study, efforts to phosphorylate MtrA using the partner kinase of MtrB failed (data not shown). Importantly, using several different methods, we showed that the nonphosphorylated MtrA could bind to the target DNA very well, suggesting that the form of MtrA might be involved in regulating the expression of its target genes. Obviously, the regulation mechanism of MtrAB needs to be further addressed in the future.
Attempts to disrupt the mtrA gene in M. tuberculosis have been unsuccessful; thus, $m$ trA seems to be an essential gene for $M$. tuberculosis proliferation [11]. The genes encoding the MtrAB two-component system of C. glutamicum were deleted successfully, and this deletion strongly influenced the cell morphology, antibiotic susceptibility, and expression of genes involved in osmoprotection [15]. In the current study, a large group of target genes for MtrA was characterized from the genomes of both $M$. tuberculosis and M. smegmatis, including multiple transcriptional factors such as TetR family regulators, stress gene family protein (MSMEG_3308), and the isoniazid inducible protein IniA (MSMEG_0695). Inhibition of the $m t r A$ gene, therefore, resulted in corresponding 


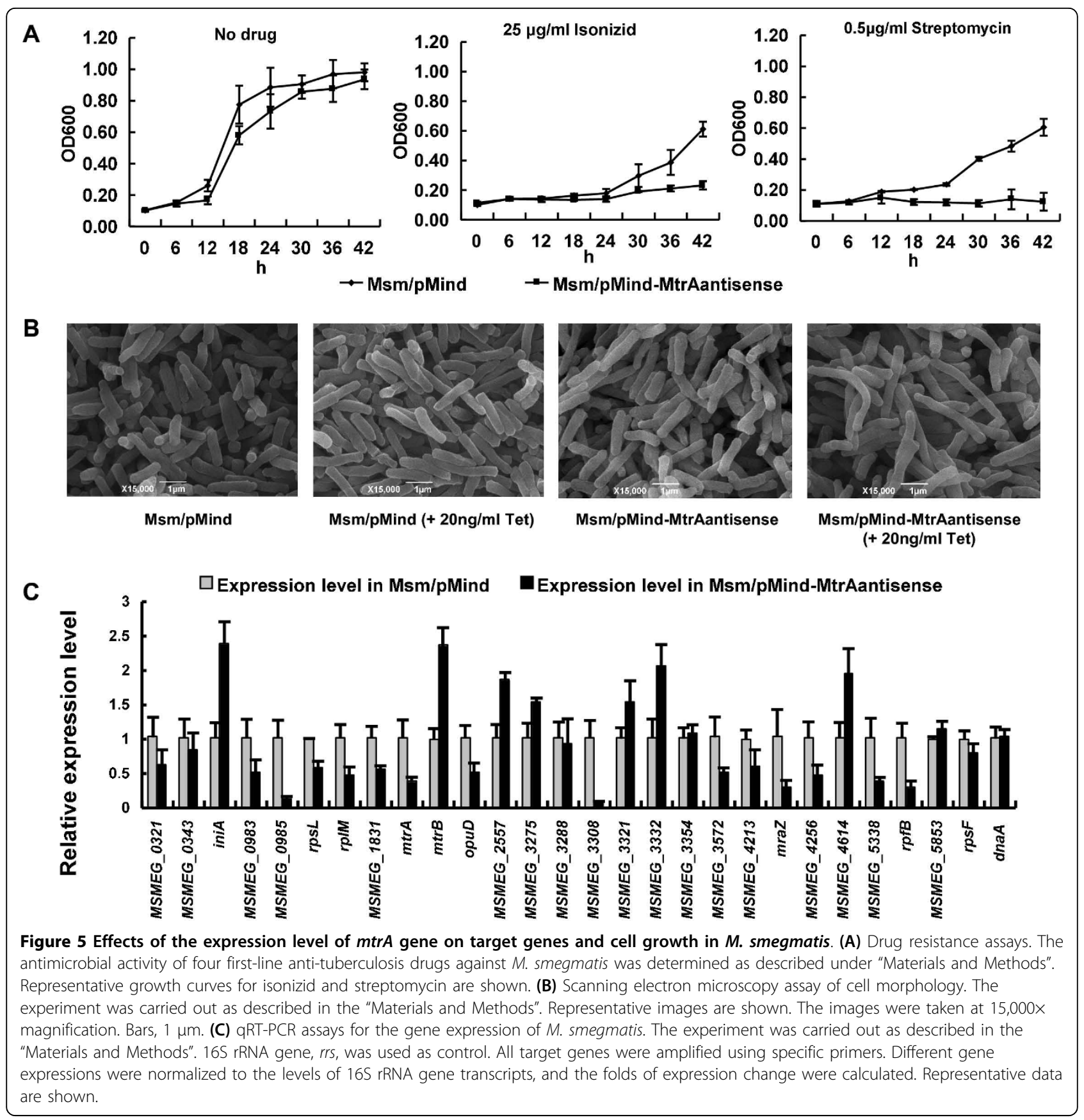

expression changes in many or all of these target genes in M. smegmatis (Fig. 5C).

In the current study, we found the conserved motifs of the MtrAB two-component system upstream of a large list of genes that have several different functions, including cell cycle progression regulation, secreted antigen, and drug resistance. Interestingly, as shown in Additional file 6 , there are 42 genes $(10 \%)$ that were found in both mycobacterial species. MtrA was reported to be involved in the transcriptional regulation of $d n a A$ in
M. tuberculosis; this provides the first direct evidence of its role in cell cycle progression [12]. In M. avium, MtrAB could respond to general stresses and ultimately inhibit cell division [14]. A recent study found that the promoter for immunodominant secreted antigen $85 \mathrm{~B}$ was also characterized as the targets of MtrA [13]. Therefore, our findings were consistent with these previous studies.

Among the many predicted target genes, there are drug resistance and transport-related genes (including 
the isoniazid inducible gene $i n i B)$, a probable transport integral membrane gene, and osmoprotection-related genes. The operon iniBAC was previously found to confer multidrug tolerance to $M$. bovis BCG through an associated pump-like activity, and was induced by isoniazid and ethambutol $[19,20]$. These findings suggest that the $m t r A$ gene might be involved in drug resistance. In the current study, we have confirmed that MtrA could bind the iniB promoter region. The recombinant $M$. smegmatis strain was found to become sensitive to the anti-TB drugs, isoniazid and streptomycin, when $m$ trA gene expression was inhibited by an antisense mRNA technique (Fig. 5A). In M. avium, mtrAB was shown to play a role in regulating the composition and permeability of mycobacterial cell walls and was required for morphotypic multidrug resistance [14]. In the current study, the recombinant $M$. smegmatis cells were observed to increase in length. This is most likely due to the changes of the mycobacterial cell wall, which would contribute to mycobacterial sensitivity to anti-TB drugs. All evidence makes MtrA a good target candidate for drug design.

\section{Conclusions}

The two-component systems of $M$. tuberculosis are apparently required for its growth and resistance in hostile host environments, in which MtrAB has been reported to regulate the expression of the $M$. tuberculosis replication initiator gene, $d n a A$. In the current study, we have identified the conserved sites for the recognition of MtrA in the $d n a A$ promoter as well as approximately 420 potential target genes. Further in vivo studies about a related organism, $M$. smegmatis, reveal changes in both cell morphology and drug resistance when MtrA gene expression is inhibited. The data presented here significantly enhance our understanding of the regulatory mechanisms of the essential two-component MtrAB system and its role in the drug resistance of $M$. smegmatis.

\section{Methods}

\section{Cloning, expression and purification of recombinant proteins}

All DNA primers (Additional file 7) and oligonucleotides (Additional file 8) were synthesized by Invitrogen. M. tuberculosis mtrA was amplified using primers from genomic DNA. The MtrA genes were cloned into the overexpression vectors pET28a or pGEX-4T-1 to produce recombinant plasmids (Additional file 1). E. coli BL21(DE3) cells that were transformed with the recombinant plasmid were grown at $37^{\circ} \mathrm{C}$ in $1 \mathrm{~L}$ of $\mathrm{LB}$ medium containing $30 \mu \mathrm{g} / \mathrm{mL}$ kanamycin or $100 \mu \mathrm{g} / \mathrm{mL}$ ampicillin, respectively. Protein purification was carried out as described in earlier reports [21-24].

\section{Bacterial one-hybrid analysis}

The interaction between the regulatory region of the M. tuberculosis dnaA gene and MtrA was assayed using the bacterial one-hybrid technique [24]. The reporter vector $\mathrm{pBXcmT}$ and $\mathrm{pTRG}$ vectors containing MtrA were generated (Additional file 1). The bacterial one-hybrid assays were carried out as described in a previous study [24]. Positive growth co-transformants were selected on the screening medium plate containing $15 \mathrm{mM} \mathrm{3-AT}$, $8 \mu \mathrm{g} / \mathrm{ml}$ streptomycin, $15 \mu \mathrm{g} / \mathrm{ml}$ tetracycline, $34 \mu \mathrm{g} / \mathrm{ml}$ chloramphenicol, and $50 \mu \mathrm{g} / \mathrm{ml}$ kanamycin.

\section{Electrophoretic Mobility Shift Assay (EMSA)}

The double-stranded substrates were prepared according to a previously published procedure [21]. DNA-binding assays of M. tuberculosis MtrA and its mutant proteins were performed using a modified electrophoretic mobility shift assay (EMSA), as previously described [21-23] but with several changes. The reactions $(10 \mu \mathrm{L})$ for measuring the mobility shift contained $200 \mathrm{fmol}{ }^{32} \mathrm{P}$-labeled DNA and various amounts of MtrA diluted in a buffer containing $20 \mathrm{mM}$ Tris- $\mathrm{HCl}$ ( $\mathrm{pH} 7.5), 100 \mathrm{mM} \mathrm{NaCl}$, $0.5 \mathrm{mM} \mathrm{MgCl} 2,10 \mu \mathrm{g} / \mathrm{ml}$ sonicated salmon sperm DNA, $0.7 \mathrm{mM}$ 2-mercaptoethanol and 5\% glycerol. Reactions were performed and gels were exposed to a storage-phosphor screen overnight at room temperature. The images were acquired using a Typhoon scanner (GE Healthcare).

\section{Surface Plasmon Resonance (SPR) analysis}

The interaction between the regulatory region of the $M$. tuberculosis dnaA gene was assayed using SPR. Biotin-labeled promoter DNA was immobilized onto a SA chip (BIAcore), based on a previously published procedure [24]. The purified MtrA protein was passed over the chip. DNA-protein interaction assays were performed at $25^{\circ} \mathrm{C}$. Each analysis was performed in triplicate. An overlay plot was generated to illustrate the interactions.

\section{Scanning Electron Microscopy (SEM) observation}

M. smegmatis cells prepared for scanning electron microscopy (SEM) observation were grown in LB for 24 hours in the presence of $20 \mathrm{ng} \cdot \mathrm{mL}^{-1}$ tetracycline. Cells were harvested by centrifugation. The bacterial pellets were resuspended and incubated at $4{ }^{\circ} \mathrm{C}$ for 24 hours in $2.5 \%$ glutardialdehyde solution. The cells were washed twice in double distilled water and then dehydrated by $15 \mathrm{~min}$ treatments in 30, 50, 75, 85, 95 and $100 \%$ ethanol. The incubation in $100 \%$ ethanol was repeated to ensure complete dehydration. Samples were critical-point dried, sputter-coated with gold, and observed using a scanning electron microscope (S570; Hitachi, Tokyo, Japan). Representative images are shown. 


\section{Quantitative real-time PCR (qRT-PCR)}

For real-time PCR analysis, gene-specific primers (Additional file 9) were used and first-strand cDNAs were synthesized using SuperScript II reverse transcriptase (Invitrogen), according to the manufacturer's instructions. Each PCR reaction $(10 \mu \mathrm{l})$ contained $10 \mu \mathrm{l}$ of $2 \times$ SYBR Green Master Mix Reagent (Applied Biosystems), $1.0 \mu \mathrm{l}$ of cDNA samples, and $200 \mathrm{nM}$ gene-specific primers. The thermocycling conditions were $95^{\circ} \mathrm{C}$ for $5 \mathrm{~min}$, and 40 cycles at $95^{\circ} \mathrm{C}$ for $30 \mathrm{~s}, 60^{\circ} \mathrm{C}$ for $30 \mathrm{~s}$ and $72^{\circ} \mathrm{C}$ for $30 \mathrm{~s}$. Amplification specificity was assessed using melting curve analysis. Different gene expressions were normalized to the levels of $16 \mathrm{~S}$ rRNA gene transcripts [15]. The degrees of expression change were calculated using the $2^{-\Delta \Delta \mathrm{Ct}}$ method [25].

\section{Drug resistance assays}

The antimicrobial activity of four first-line anti-tuberculosis drugs against $M$. smegmatis was determined using a modified bacterial growth time course assay. M. smegmatis was grown in $\mathrm{LB}$ at $37^{\circ} \mathrm{C}$ overnight. This culture was then diluted (1:100) in $5 \mathrm{ml}$ of fresh LB broth containing the indicated concentration of each drug, and the culture was again incubated at $37^{\circ} \mathrm{C}$ with shaking at $220 \mathrm{rpm}$ for two days. Samples were taken at various time points $(0,6,12$, $18,24,30,36,42$, and $48 \mathrm{~h}$ ). Optical density was measured at $600 \mathrm{~nm}\left(\mathrm{OD}_{600}\right)$ using a Beckman DU650 spectrophotometer. All assays were performed three times. Representative growth curves are shown.

\section{DNase I footprinting assays}

The $84 \mathrm{bp}$ (S6) and $75 \mathrm{bp}$ (S7) dnaA promoter regions were amplified (dnaAf1 and dnaAr2 were used to amplify S6 from genomic DNA, while dnaAf3 and dnaAr4 were used to amplify S7) (Additional file 7) and cleaved by endonuclease EcoRI, leaving a sticky 5 ' end that was five nucleotides from the original end. The recessive 3' end was labeled with $\left[\alpha-{ }^{32} \mathrm{P}\right]$ dATP (Furui Biotech, Beijing, China) by the Klenow fragment, and then subjected to the same binding reaction as in the electrophoretic mobility shift assay. DNase I footprinting was performed as previously described [26]. The ladders were produced using the Sanger dideoxy method and dnaAf1 and dnaAf3 primers that were end-labeled by T4 polynucleotide kinase and $\left[\gamma_{-}{ }^{32} \mathrm{P}\right]$ ATP (Furui Biotech, Beijing, China), respectively.

\section{Bioinformatics assays on the distribution of the identified 7 bp motif within mycobacterial genomes}

The regulatory sequences were collected from the complete genomes of $M$. tuberculosis and M. smegmatis and the database of intergenic regions of ORFs (from stop codon to start codon) were constructed. The exact motifs (CACGCCG or CACGAGG) were then used to search for the distribution of the identified 7 bp motifs in the M. tuberculosis $\mathrm{H} 37 \mathrm{Rv}$ and the M. smegmatis genomes. The identified target genes are listed (Additional file 10 and Additional file 11).

\section{Additional material}

\begin{abstract}
Additional file 1: Plasmids and recombinant vectors used in this study. The data present plasmids and recombinant vectors used in this study.

Additional file 2: SPR assays for the binding of unspecific promoter chip by MtrA. The data present SPR assays for the binding of unspecific promoter chip by MtrA.

Additional file 3: Competing SPR assay with the unlabeled DNA fragments for the binding of the promoter chip by MtrA. The data present the competing SPR assay with the unlabeled DNA fragments for the binding of the promoter chip by MtrA.

Additional file 4: Potential target genes for MtrA in M. tuberculosis The data provided potential target genes for MtrA in M. tuberculosis.

Additional file 5: Potential target genes for MtrA in M.smegmatis. The data present Potential target genes for MtrA in M.smegmatis.

Additional file 6: Homologous target genes recognized by MtrA in M. tuberculosis and $\boldsymbol{M}$. smegmatis. The data present homologous target genes recognized by MtrA in $M$. tuberculosis and M. smegmatis.

Additional file 7: Primers used in this study. The data provided primers used in this study.

Additional file 8: Sequences of the DNA substrates used in this study. The data provided sequences of the DNA substrates used in this study.

Additional file 9: Primers used for quantitative real time PCR in this study. The data present the primers used for quantitative real time PCR in this study.

Additional file 10: Classification and percentage of the target genes containing the 7-bp motif recognized by MtrA in $\mathbf{M}$. smegmatis. The data present the categories and percentage of the target genes containing the 7-bp motif recognized by MtrA in M. smegmatis.

Additional file 11: The data present the categories and percentage of the target genes containing the 7-bp motif recognized by MtrA in $\boldsymbol{M}$. tuberculosis. The data present the categories and percentage of the target genes containing the 7-bp motif recognized by MtrA in M. tuberculosis.
\end{abstract}

\section{Abbreviations}

3-AT: 3-amino-1, 2, 4-triazole; EMSA: electrophoretic mobility shift assay; PCR: polymerase chain reaction; qRT-PCR: Quantitative real-time PCR; SA chips: Streptavidin chip; SEM: scanning electron microscopy; SPR: surface plasmon resonance; TCRs: two-component systems

\section{Acknowledgements}

We thank Prof. Yi Zhang and her group members for help with footprinting assays. This work was supported by the National Natural Science Foundation of China (30930003) and 973 Program (2006CB504402).

\section{Authors' contributions}

$Y L$ and ZGH designed the experiments. $Y L$ and JZ performed the experiments. YL HZ and ZGH analyzed the data. ZGH contributed reagents/ materials/analysis tools. ZGH and $\mathrm{YL}$ wrote the paper. All authors have read and approved the final manuscript.

\section{Competing interests}

The authors declare that they have no competing interests. 
Received: 26 May 2010 Accepted: 16 September 2010

Published: 16 September 2010

\section{References}

1. Johnson R, Streicher EM, Louw GE, Warren RM, van Helden PD, Victor TC: Drug resistance in Mycobacterium tuberculosis. Curr Issues Mol Biol 2006, 8(2):97-111.

2. Wright A, Zignol M, Van Deun A, Falzon D, Gerdes SR, Feldman K, Hoffner S, Drobniewski F, Barrera L, van Soolingen D, Boulabhal F, Paramasivan CN, Kam KM, Mitarai S, Nunn P, Raviglione M, Global Project on Anti-Tuberculosis Drug Resistance Surveillance: Epidemiology of antituberculosis drug resistance 2002-07: an updated analysis of the Global Project on Anti-Tuberculosis Drug Resistance Surveillance. Lancet 2009, 373(9678):1861-1873.

3. Beier D, Gross R: Regulation of bacterial virulence by two-component systems. Curr Opin Microbiol 2006, 9(2):143-152.

4. Stock AM, Robinson VL, Goudreau PN: Two-component signal transduction. Annu Rev Biochem 2000, 69:183-215.

5. Cole ST, Brosch R, Parkhill J, Garnier T, Churcher C, Harris D, Gordon SV, Eiglmeier K, Gas S, Barry CE, Tekaia F, Badcock K, Basham D, Brown D, Chillingworth T, Connor R, Davies R, Devlin K, Feltwell T, Gentles $S$, Hamlin N, Holroyd S, Hornsby T, Jagels K, Krogh A, McLean J, Moule S, Murphy L, Oliver K, Osborne J, et al: Deciphering the biology of Mycobacterium tuberculosis from the complete genome sequence. Nature 1998, 393(6685):537-544.

6. Zahrt TC, Deretic V: Mycobacterium tuberculosis signal transduction system required for persistent infections. Proc Natl Acad Sci USA 2001, 98(22):12706-12711.

7. Ewann F, Jackson M, Pethe K, Cooper A, Mielcarek N, Ensergueix D, Gicquel B, Locht C, Supply P: Transient requirement of the PrrA-PrrB twocomponent system for early intracellular multiplication of Mycobacterium tuberculosis. Infect Immun 2002, 70(5):2256-2263.

8. Park HD, Guinn KM, Harrell MI, Liao R, Voskuil MI, Tompa M, Schoolnik GK, Sherman DR: Rv3133c/dosR is a transcription factor that mediates the hypoxic response of Mycobacterium tuberculosis. Mol Microbiol 2003, 48(3):833-843.

9. Parish T, Smith DA, Kendall S, Casali N, Bancroft GJ, Stoker NG: Deletion of two-component regulatory systems increases the virulence of Mycobacterium tuberculosis. Infect Immun 2003, 71(3):1134-1140.

10. Via LE, Curcic R, Mudd MH, Dhandayuthapani S, Ulmer RJ, Deretic V: Elements of signal transduction in Mycobacterium tuberculosis: in vitro phosphorylation and in vivo expression of the response regulator MtrA. J Bacteriol 1996, 178(11):3314-3321.

11. Zahrt TC, Deretic V: An essential two-component signal transduction system in Mycobacterium tuberculosis. J Bacteriol 2000, 182(13):3832-3838.

12. Fol M, Chauhan A, Nair NK, Maloney E, Moomey M, Jagannath C, Madiraju MV, Rajagopalan M: Modulation of Mycobacterium tuberculosis proliferation by MtrA, an essential two-component response regulator. Mol Microbiol 2006, 60(3):643-657.

13. Rajagopalan M, Dziedzic R, Al Zayer M, Stankowska D, Ouimet MC, Bastedo DP, Marczynski GT, Madiraju MV: The Mycobacterium tuberculosis origin of replication and the promoter for immunodominant secreted antigen $85 \mathrm{~B}$ are the targets of MtrA, the essential response regulator. $J$ Biol Chem 2010, 285(21):15816-15827.

14. Cangelosi GA, Do JS, Freeman R, Bennett JG, Semret M, Behr MA: The twocomponent regulatory system mtrAB is required for morphotypic multidrug resistance in Mycobacterium avium. Antimicrob Agents Chemother 2006, 50(2):461-468.

15. Möker N, Brocker M, Schaffer S, Krämer R, Morbach S, Bott M: Deletion of the genes encoding the MtrA-MtrB two-component system of Corynebacterium glutamicum has a strong influence on cell morphology, antibiotics susceptibility and expression of genes involved in osmoprotection. Mol Microbiol 2004, 54(2):420-438.

16. Crooks GE, Hon G, Chandonia JM, Brenner SE: WebLogo: A sequence logo generator. Genome Res 2004, 14(6):1188-1190.

17. Blokpoel MC, Murphy HN, O'Toole R, Wiles S, Runn ES, Stewart GR, Young DB, Robertson BD: Tetracycline-inducible gene regulation in mycobacteria. Nucleic Acids Res 2005, 33(2):e22.

18. Salazar L, Guerrero E, Casart Y, Turcios L, Bartoli F: Transcription analysis of the dnaA gene and oriC region of the chromosome of Mycobacterium smegmatis and Mycobacterium bovis BCG, and its regulation by the DnaA protein. Microbiology 2003, 149(Pt 3):773-784.

19. Colangeli $R$, Helb D, Sridharan S, Sun J, Varma-Basil M, Hazbón MH, Harbacheuski R, Megjugorac NJ, Jacobs WR Jr, Holzenburg A, Sacchettini JC, Alland D: The Mycobacterium tuberculosis iniA gene is essential for activity of an efflux pump that confers drug tolerance to both isoniazid and ethambutol. Mol Microbiol 2005, 55(6):1829-1840.

20. Alland D, Steyn AJ, Weisbrod T, Aldrich K, Jacobs WR Jr: Characterization of the Mycobacterium tuberculosis iniBAC promoter, a promoter that responds to cell wall biosynthesis inhibition. J Bacterio/ 2000, 182(7):1802-1811.

21. He ZG, Rezende LF, Willcox S, Griffith JD, Richardson CC: The carboxylterminal domain of bacteriophage T7 single-stranded DNA-binding protein modulates DNA binding and interaction with T7 DNA polymerase. J Biol Chem 2003, 278(32):29538-29545.

22. Jiang PX, Wang J, Feng Y, He ZG: Divergent functions of multiple eukaryote-like Orc1/Cdc6 proteins on modulating the loading of the MCM helicase onto the origins of the hyperthermophilic archaeon Sulfolobus solfataricus P2. Biochem Biophys Res Commun 2007, 361(3):651-658.

23. Wang J, Jiang PX, Feng H, Feng $Y$, He ZG: Three eukaryote-like Orc1/Cdc6 proteins functionally interact and mutually regulate their activities of binding to the replication origin in the hyperthermophilic archaeon Sulfolobus solfataricus P2. Biochem Biophys Res Commun 2007, 363(1):63-70.

24. Guo M, Feng H, Zhang J, Wang W, Wang Y, Li Y, Gao C, Chen H, Feng Y, He ZG: Dissecting transcription regulatory pathways through a new bacterial one-hybrid reporter system. Genome Res 2009, 19(7):1301-1308.

25. Livak KJ, Schmittgen TD: Analysis of relative gene expression data using real-time quantitative PCR and the $2^{-\Delta \Delta C t}$ method. Methods 2001, 25(4):402-408.

26. Yin $P$, Li TY, Xie MH, Jiang $L$, Zhang $Y$ : A type Ib ParB protein involved in plasmid partitioning in a Gram-positive bacterium. J Bacteriol 2006, 188(23):8103-8108.

\section{doi:10.1186/1471-2180-10-242}

Cite this article as: Li et al:: The characterization of conserved binding motifs and potential target genes for $M$. tuberculosis MtrAB reveals a link between the two-component system and the drug resistance of $M$. smegmatis. BMC Microbiology 2010 10:242.

\section{Submit your next manuscript to BioMed Central and take full advantage of:}

- Convenient online submission

- Thorough peer review

- No space constraints or color figure charges

- Immediate publication on acceptance

- Inclusion in PubMed, CAS, Scopus and Google Scholar

- Research which is freely available for redistribution

Submit your manuscript at www.biomedcentral.com/submit
C Biomed Central 